\title{
A STUDY TO FIND THE DISTRIBUTION OF ABO BLOOD GROUP IN BETA THALASSEMIA
}

\author{
Physiology \\ Dr. Shefali D. \\ Solanki \\ Dr Rajendra \\ Amin* \\ Associate Professor, Department Of Physiology, B. J. Medical College, A'bad. \\ *Corresponding Author
}

\section{ABSTRACT}

INTRODUCTION: - Beta thalassemia ( $\beta$-thalassemia) is an inherited hematological disorder involving decreased amount of hemoglobin production. It is a major problem of concern causing high mortality rates in children. Thalassemia patients suffer from severe anemia due to which they need to get repeated blood transfusion after a regular period of time. Many studies have reported association of ABO blood group with diseases. AIM AND OBJECTIVES: - To study the relation between the ABO blood group and beta thalassemia. MATERIALS AND METHODS: - This was a cross sectional, observational survey-based on study conducted at Dept. of Physiology, A'bad with the help of Thalassemia Care Centre, Civil Hospital, Ahmedabad. The study was conducted on 300 registered beta thalassemia major patients during February 2019 to August 2019 over a period of 6 months. These patients visited the thalassemia care center for repeated blood transfusion. Blood group of the patient was determined by Slide Agglutination Method at Department of Physiology. Results were prepared \& tabulated in Microsoft Excel 2013. RESULTS: - It is found that among the study that males were more affected than females. It is more prevalent in Rh positive individuals as compared to Rh negative. Frequency of blood groups affecting patients were $\mathrm{O}>\mathrm{B}>\mathrm{A}>\mathrm{AB}$. CONCLUSION: - Thalassemia is more prevalent in males than females. The most commonly affected blood group is $\mathrm{O}$ positive followed by $\mathrm{B}$ positive, A positive and last $\mathrm{AB}$ positive. Among the $\mathrm{Rh}$ blood group, Rh positive were more as compared to Rh negative but Rh-negative females were more common than Rh positive males.

\section{KEYWORDS}

Thalassemia, ABO Blood group, RH blood group.

\section{INTRODUCTION}

Thalassemia are group of inherited hematological disorder involving decreased amounts of hemoglobin production (2). It is caused by the mutations in the DNA of cells that make hemoglobin molecule which is responsible for carrying oxygen throughout the body. It is a major problem of concern causing high mortality rates in children. These diseases are passed on from parents to their children.

Hemoglobin molecules are normally made up of alpha $(\alpha)$ globin chains and beta $(\beta)$ globin chains. These chains are affected by the mutations which can cause reduced production of chains or abnormal RBCs (5). Based on the type of chains affected, thalassemia is differentiated into alpha thalassemia and beta thalassemia. The severity of this depends on how many of the four chains of $\alpha$ globin or two chains of $\beta$ globin are affected. The $\beta$ form is particularly more common and prevalent among the Mediterranean people (9).

Beta Thalassemia is caused by the reduced or absent synthesis of $\beta$ chains of hemoglobin that result in variable outcome ranging from severe anemia to clinically asymptomatic individuals. $\beta$-thalassemia occur due to malfunctions in the hemoglobin subunit beta. The $\beta$ globin gene is located on chromosome number 11. $\beta$ thalassemia occur in 3 forms: $\beta$ thalassemia minor, $\beta$ thalassemia intermedia $\& \beta$ thalassemia major. $\beta$ thalassemia major is the most severe form in which patient's body is unable to construct beta chains which leads to underproduction of $\mathrm{HbA}$ that causes microcytic anemia. Individuals present with severe anemia due to ineffective erythropoiesis and increased RBC destruction, poor growth and skeletal abnormalities during infancy $(2,4)$. Patients need to get repeated blood transfusion after a regular period of time. Many studies have reported association of ABO blood group with diseases (4). This study is done in order to explore the relationship between blood groups and $\beta$ thalassemia and to meet the regional demand of blood groups of patients.

\section{MATERIAL \& METHODS: -}

This was a cross sectional, observational survey-based study conducted at Department of Physiology, B J Medical college, Ahmedabad in collaboration with Thalassemia Care Centre, Civil Hospital, Ahmedabad. The study was conducted on 300 registered beta thalassemia major patients during February 2019 to August 2019 over a period of 6 months. These patients visited the thalassemia care center for repeated blood transfusion. After approval from the center and informed consent of the patients, patients were tested for ABO blood group and $\mathrm{Rh}$ blood group at Department laboratory by slide agglutination technique. $2.5 \%$ suspension of $\mathrm{RBC}$ was prepared in $0.9 \mathrm{~g} / \mathrm{dl}$ NS. A drop of Anti-A, Anti-B and Anti-D human polyclonal serum was placed on the different slides and to each of them was added a drop of RBC suspension with the help of pipette (5). With separate stirrer the serum was mixed with suspension and observe for agglutination after 5 minutes. Results were prepared and tabulated in Microsoft Excel 2013

RESULTS AND DISCUSSION: -

The data regarding gender, age, groups and the types of $\mathrm{ABO}$ blood groups was collected and analyzed for statistical analysis using Microsoft Excel 2013. Data was expressed as mean, standard deviation and percentage as an when required. Chi square test was used to find out significant association and $\mathrm{p}$ value $<0.05$ was considered significant

Table 1: Distribution of $\mathrm{ABO}$ blood group in beta thalassemia patient.

\begin{tabular}{|l|l|l|}
\hline VARIABLE & $\begin{array}{l}\text { NUMBER OF } \\
\text { PATIENTS }\end{array}$ & \% POPULATION \\
\hline ABO BLOOD GROUP & & \\
\hline A & 60 & $20 \%$ \\
\hline B & 91 & $30.34 \%$ \\
\hline AB & 35 & $11.66 \%$ \\
\hline O & 114 & $38 \%$ \\
\hline Total & 300 & $100 \%$ \\
\hline RH BLOOD GROUP & & \\
\hline Rh positive & 288 & $96 \%$ \\
\hline Rh negative & 12 & $4 \%$ \\
\hline GENDER & & \\
\hline Male & 185 & $61.67 \%$ \\
\hline Female & 115 & $38.33 \%$ \\
\hline AGE (IN YEARS) & & \\
\hline Age less than 5 & 132 & $44 \%$ \\
\hline $5-10$ & 97 & $32.34 \%$ \\
\hline $10-15$ & 59 & $19.66 \%$ \\
\hline More than 15 & 12 & $4 \%$ \\
\hline
\end{tabular}

Table 2: Gender and blood group wise distribution of thalassemia patients.

\begin{tabular}{|l|l|l|l|}
\hline & \multicolumn{3}{|l|}{ Male } \\
\hline Bld. Grp. & Rh +ve & Rh -ve & Overall \\
\hline
\end{tabular}




\begin{tabular}{|c|c|c|c|}
\hline $\mathbf{A}$ & $32(10.66 \%)$ & $1(0.33 \%)$ & $33(11 \%)$ \\
\hline B & $56(18.66 \%)$ & $1(0.33 \%)$ & $57(19 \%)$ \\
\hline$\overline{\mathrm{AB}}$ & $24(8 \%)$ & \begin{tabular}{|l|}
$1(0.33 \%)$ \\
\end{tabular} & $25(8.33 \%)$ \\
\hline $\mathbf{O}$ & $68(22.66 \%)$ & $2(0.66 \%)$ & $70(23.33 \%)$ \\
\hline \multirow[t]{2}{*}{ Total } & 180 & $5(1.66 \%)$ & $185(61.66 \%)$ \\
\hline & Female & & \\
\hline Bld. grp. & Rh +ve & Rh -ve & Overall \\
\hline A & $26(8.66 \%)$ & $1(0.33 \%)$ & $27(9 \%)$ \\
\hline $\mathbf{B}$ & $32(10.66 \%)$ & $2(0.66 \%)$ & $34(11.33 \%)$ \\
\hline$\overline{A B}$ & $9(3 \%)$ & $1(0.33 \%)$ & $10(3.33 \%)$ \\
\hline $\mathbf{O}$ & $41(13.66 \%)$ & $3(1 \%)$ & $44(14.66 \%)$ \\
\hline
\end{tabular}

Table 3: Distribution of $\mathrm{ABO}$ blood group in beta-thalassemia patients according to gender

\begin{tabular}{|l|l|l|l|l|}
\hline Blood group & Male & Female & Chi & p-value \\
\hline A & 33 & 27 & 1.42 & 0.2 \\
\hline B & 57 & 34 & 0.05 & 0.8 \\
\hline AB & 25 & 10 & 1.51 & 0.2 \\
\hline O & 70 & 44 & 0.005 & 0.9 \\
\hline Rhesus Factor & Male & Female & Chi & p-value \\
\hline Positive & 180 & 108 & 2.11 & 0.14 \\
\hline Negative & 5 & 7 & & \\
\hline Age (in yrs) & Male & Female & Chi & p-value \\
\hline$<\mathbf{5}$ & 78 & 54 & 0.66 & 0.4 \\
\hline $\mathbf{5 - 1 0}$ & 60 & 37 & 0.002 & 0.9 \\
\hline $\mathbf{1 0 - 1 5}$ & 39 & 20 & 0.61 & 0.4 \\
\hline$>\mathbf{1 5}$ & 8 & 4 & 0.13 & 0.7 \\
\hline
\end{tabular}

As per the Table 1 shows, prevalence of beta thalassemia among $\mathrm{ABO}$ blood group is in order of $\mathrm{O}>\mathrm{B}>\mathrm{A}>\mathrm{AB}$.It is found that among the study of 300 cases, the maximum patients were of $\mathrm{O}$ blood group (38\%) followed by B blood group (30.34\%), later by A blood group $(20 \%)$ and least were of $A B$ blood group $(11.66 \%)$. In study population, males $(\mathrm{n}=185)$ were more affected than females $(\mathrm{n}=115)$. It is more prevalent in $\mathrm{Rh}$ positive blood group individuals $(\mathrm{n}=288)$ as compared to $\mathrm{Rh}$ negative $(\mathrm{n}=12)$. Among the age distribution, children less than 5 years of age were more affected $(\mathrm{n}=132)$ which is about $44 \%$ of study population, whereas the children of age group 5-10 years were 97 in number comprising of about $32.34 \%$ of population. Also, the children of age 10-15 years and above 15 years were 59 and 12 respectively which contributed to about 19.66 and $4 \%$ of study population

In Table 2, distribution of thalassemia according to gender shows that $O$ positive males were more commonly affected $(n=68,22.66 \%)$ and among females, prevalence was more in $O$ positive females $(n=41$, $13.66 \%$ ). The order of prevalence in each gender in $\mathrm{Rh}$ positive individuals was same as in general distribution, i.e., $\mathrm{O}>\mathrm{B}>\mathrm{A}>\mathrm{AB}$. On the contrary, females were more affected as compared to males amongst the Rh-negative individuals. In Table 3, on applying Chisquare test there was no significant correlation in distribution of blood group among males and females and in $\mathrm{Rh}$ positive and $\mathrm{Rh}$ negative people.

\section{DISCUSSION: -}

Amongst all the 3 forms of beta thalassemia, beta thalassemia major have severe expression of the disorder hence they require regular blood transfusion. Thalassemia patients need repeated transfusion so it is necessary to determine the frequency of $\mathrm{ABO}$ blood groups. As per our study we found that males were more commonly affected than females which is in agreement with other studies like Laghari (2017), Khan (2015) and Bejaoui $(2013)(1,9,10)$. We also found in our studies the prevalence of beta thalassemia was more among $\mathrm{Rh}$ positive individuals than $\mathrm{Rh}$ Negative individuals $(1,5,6)$. On contrary we have also found more prevalence among $\mathrm{Rh}$ negative females than males particularly $\mathrm{O}$ negative (1). The ABO blood group affected were in order of $\mathrm{O}>\mathrm{B}>\mathrm{A}>\mathrm{AB}$ in males and females in our studies which is also found in studies like Sarah (2018), Sinha (2017), Laghari (2017) and Verma (2013). On contrary we have also found more prevalence among rh negative females than males. Among the age distribution we found that children less than 5 years are more commonly affected than other age group as this disease is an inherited and occurs in infancy (10). Similar pattern is also seen in study of Laghari (1). This all findings needs further investigations and evaluations. commonly affected blood group is $\mathrm{O}$ positive followed by $\mathrm{B}$ positive, $\mathrm{A}$ positive and last $\mathrm{AB}$ positive. Among the $\mathrm{Rh}$ blood group, Rh positive were more affected as compared to $\mathrm{Rh}$ negative but $\mathrm{Rh}$-negative females were higher than Rh positive males. This study will be helpful in making public health policies for blood availability for patients with thalassemia as per regional demand.

\section{ACKNOLEDGEMENT:-}

I am thankful to the Thalassemia Day Care, Civil Hospital, my teachers and the patients who helped me to do this study.

Conflicts of interest: none declared

Ethical approval: not required

\section{REFERENCES:}

1. Z. A. Laghari, N. M. Baig, T. R. Charan, K. H. Lashari, R. Suhag, "Distribution of ABO Blood Groups and Rhesus Factor In $\beta$-Thalassemia Patients at Thalassemia Care Center NawabShah, Pakistan.”, Sindh Univ. Res. Jour. (Sci. Ser.) Vol. 50 (001) 123-128(2018).

2. Sinha PA, Mulkutkar SH, Bhavani JB. Study of distribution of ABO blood groups in $\beta$ thalassemia patients. Int J Res Med Sci 2017;5:3479-83.

3. Hananjassim Hammod, Thanaa Abdulmahdi Mokif, Hussein Jasim Al-Harbi, "The correlation between thalassemia with body mass index and blood groups in children and

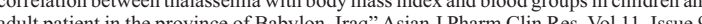
adult patient in

4. Mohssin MY, Mahmood AE, Kamal SB, Batah EH. Frequency distribution of hemoglobin variant and $\mathrm{ABO}$ blood groups among thalassemia patients from Ibn-AlBaladi pediatric hospital in Baghdad/Iraq. W J Pharma Pharmaceut Sci. 2015;4(11):319 .

5. Sarah M. Mahmoud Marbut, Maha A. Hamdi, Abdulhadi M.Jumaa, Basma Abbas Salman, "Distribution of ABO blood groups in beta thalassemia patients dependent on blood transfusion In Bagdad city." Journal Of Madent Alelem College VOL 10 NO 2 YEAR 2018

6. Verma, P., (2013). "Prevalence of Heamoglobin Variants, ABO and Rhesus Blood Groups in Northern Uttar Pradesh, India." Biomedical Research 24(3).

7. Saha AK, Sahadalal BS. Frequency and distribution of blood groups in the donors of a rural hospitals, West Bengal, India. Int J Pharma Bio Sci. 2016;7(1):B414-8.

8. Iqbal M, Niazi A, Tahir M. Frequency of ABO and Rh blood groups in healthy donors. J Rawalpindi Med Coll. 2009;13(2);92-4

9. Bejaoui, M. and N. Guirat (2013). "Beta thalassemia major in a developing country: epidemiological, clinical and evolutionary aspects." Mediterranean journal of hematology and infectious diseases $5(1)$

10. Dr. Vandana Bharadwaj, Dr. Maneesh Sulya. "Study Of Abo Blood Group Distribution In $\beta$-thalassemia Patients In A Tertiary Care Hospital " Indian Journal Of Applied Research, Volume-9, Issue-7, July-2019, PRINT ISSN No. 2249-555X
CONCLUSION: -

Thalassemia is more prevalent in males than female. The most 